\title{
O PARFOR E SUAS CONTRIBUIÇÕES NA FORMAÇÃO DE PROFESSORES: UMA ANÁLISE NO ÂMBITO DAS AÇÕES AFIRMATIVAS.
}

\author{
Raul da Silveira Santos ${ }^{1}$ \\ Francisco Pereira de Oliveira ${ }^{2}$
}

Eixo Temático: Ações afirmativas

Resumo: Podemos definir "ações afirmativas" como um conjunto de políticas públicas e privadas de caráter compulsório, facultativo ou voluntário, ou seja, são mecanismos de inclusão de promoção da igualdade de oportunidades de ordem cultural, pedagógica e psicológica. O objetivo do presente trabalho é analisar as políticas públicas educacionais desenvolvidas no Programa Nacional de Formação de Professores da Educação Básica (PARFOR) no âmbito das ações afirmativas de Estado. Nesse sentido, pautaram-se estudos referentes à pesquisa bibliográfica em textos, revistas eletrônicas, livros e sites do governo. Ainda, houve uma compilação de trabalhos acadêmicos realizados por estudantes da Universidade Federal do Pará, onde dados estatísticos foram anunciados. A partir de então, os resultados apontaram para um Programa (PARFOR) imbricado de ações afirmativas, por meio de políticas públicas educacionais, onde o docente da educação básica tem a oportunidade de se qualificar para o trabalho e possuir formação superior de forma gratuita e de qualidade. Ainda, percebeu-se que essa ação afirmativa do PARFOR pode servir de exemplo a outros países em que a formação de docentes na educação básica ainda é deficitária. Adicionalmente, reconhece-se que dentro e meio a tantos programas educacionais propostos e implementados no Brasil, o PARFOR possui uma política pública de ação afirmativa efetivada, corrigindo, parcialmente, o déficit histórico e social de exclusão de cidadãos marginalizados nessa sociedade capitalista.

Palavras-chave: Educação Básica. PARFOR. Políticas Públicas. Ações afirmativas.

\begin{abstract}
We define "affirmative action" as a set of public and private policies of compulsory character, optional or voluntary, or are promoting inclusion mechanisms of equal opportunities for cultural, educational and psychological. The objective of this study is to analyze the educational policies developed at the National Training Programme for Education of Teachers Basic (PARFOR) under the affirmative action of

\footnotetext{
${ }^{1}$ Graduando do curso de Pedagogia, raulsantos.21@ @otmail.com, UFPA/Capanema.

${ }^{2}$ Prof. Dr. foliveiranono@ yahoo.com.br. UFPA/Bragança. Titular de Planejamento, Gestão de Sistemas e Legislação da Universidade Federal do Pará.
} 
the state. In this sense, guided studies were related to literature texts, electronic journals, books and government websites. Still, there was a compilation of academic work done by students of the Federal University of Pará, where statistical data were announced. Since then, the results pointed to a program (PARFOR) imbricated affirmative action through public educational policies, where the teaching of basic education has the opportunity to qualify for the job and has a degree of free and quality. Still, it was realized that this statement of PARFOR action can serve as an example to other countries in the training of teachers in basic education is still in deficit. In addition, it is recognized that in and through the many educational programs proposed and implemented in Brazil, PARFOR has a public policy effective affirmative action, correcting partly the historical and social deficit exclusion of marginalized citizens in this capitalist society.

Keiwords:Basic Education. PARFOR. Public policy. affirmative action.

\section{Introdução}

A princípio, justificamos o uso das medidas de ações afirmativas com o seguinte argumento: que tal prática é uma política social, com intuito de alcançar uma série de objetivos. As ações afirmativas começam a ganhar força no final dos anos oitenta e início dos anos noventa do século passado, a intenção era e ainda é a superação das desigualdades. Vale ressaltar que nesse período ações afirmativas já tinham sido adotadas por outros países, na intenção de beneficiar determinados grupos da sociedade. O termo "ação afirmativa" tem origem nos Estado Unidos, que são tidos como referência no assunto.

Pierré (2004, p. 8) "conclui que o princípio da discriminação positiva tem um papel fundamental na conciliação do aparente conflito entre princípio de igualdade de todos os cidadãos e o reconhecimento do direito a diferença”. Vale lembrar que para o Brasil, medidas de cunho social não são novidades. Desde o século XIX o Brasil vivencia a intervenção do Estado por intermédio da legislação, com o objetivo de favorecer a integração de determinado segmento da sociedade. O público alvo varia de acordo com as situações existentes, e sempre abrangem grupos como minorias étnicas, raciais e mulheres.

O presente trabalho está inserido no seguinte contexto: analisar as políticas

públicas educacionais presentes no Plano Nacional de Formação de Professores da 
Educação Básica (PARFOR) no âmbito das ações afirmativas nas políticas de governo. Algumas das problemáticas que impediram uma grande parte da população de se qualificar estarão sendo expostas no decorrer do trabalho, como também para fundamentar a ideia de benefício. O trabalho será complementado com dados estatísticos que demonstram uma série de bons resultados alcançados através do PARFOR, desde o primeiro ano de sua implementação.

\section{OBJETIVOS}

\subsection{Objetivo geral}

Analisar as políticas públicas educacionais propostas no PARFOR no âmbito das ações afirmativas, com ênfase na formação para a educação básica.

\subsection{Objetivos específicos}

Realizar estudo bibliográfico no que diz respeito às políticas públicas educacionais no PARFOR com foco nas ações afirmativas na formação docente da educação básica.

Apresentar dados oficiais estatísticos como benefícios na formação da educação básica por meio de políticas públicas no Programa PARFOR/PARÁ.

\section{METODOLOGIA}

O trabalho foi desenvolvido através de pesquisas feitas em sites, revistas eletrônicas, livros e textos, ou seja, numa abordagem qualitativa e quantitativa da pesquisa. Neste sentido, foram catalogadas diversas publicações sobre o PARFOR, inclusive trabalho de conclusão de curso, dissertações de mestrado e teses de doutorado. Ainda, foram feitas consultas nos sites oficiais do Governo Federal e Estadual no que concerne ao PARFOR. Em seguida, foram realizadas leituras e compiladas para referenciar políticas públicas de educação e ações afirmativas. Posteriormente, os dados foram dispostos numa produção dissertativa.

\section{RESULTADOS E DISCUSSÃO}

Para entendermos melhor como as ações afirmativas foram tornando-se possíveis em nosso país, precisamos citar alguns fatos históricos e sociais que contribuíram para que medidas compensatórias fossem tomadas. 
O Brasil na década de 30 do século passado passa por algumas reformas educacionais, com isso, passa a acreditar-se que a intervenção do Estado na educação seria a melhor solução para os problemas do Brasil, entre eles, os sociais, econômicos e políticos. Quanto a essas reformas, Shiroma (2002, p. 17), discorre.

\begin{abstract}
Os debates políticos que se travavam no alvorecer dos anos de 1930 incluíam um crescente interesse pelas questões educacionais. Herança de anos anteriores ganhava força entre vários intelectuais e políticos da época, a ideia de que era indispensável à modernização do Brasil a montagem de um estado nacional, centralizador, antiliberal e intervencionista. [...]. [A]s possibilidades de intervenção do processo educativo eram superestimadas a tal ponto que nele pareciam estar contidas as soluções para os problemas do país: sociais, econômicos ou políticos.
\end{abstract}

Em 1968 ocorre o debate em torno dessa questão, através do Ministério do Tribunal Superior do Trabalho, na qual os técnicos se posicionaram a favor das leis que beneficia as camadas desfavorecidas. No entanto, somente em 1980 houve a primeira formulação de uma lei nesse âmbito, ou seja, políticas de caráter compensatório. Medidas foram elaboradas, porém, esse projeto não foi aprovado pelo Congresso Nacional.

Apenas em 1988, por meio da Constituição Federal do Brasil, Artigo 37 é estabelecido um percentual dos cargos públicos para portadores de deficiência. A partir daí começam as primeiras deliberações em torno da política de ações afirmativas. E em 1995 são adotadas, nacionalmente, a primeira política de cotas, que correspondia e corresponde até os dias atuais, à reserva de $30 \%$ das vagas para mulheres exercerem atividades em cargos públicos.

Em 2007, com a adesão do "Plano de Metas e Compromisso Todos pela Educação", foi estabelecido no país um regime de colaboração entre a União com os estados e municípios, com a intenção de assegurar a formação exigida por Lei de Diretrizes e Bases da Educação Nacional (LDB), Lei $\mathrm{N}^{\circ}$ 9.394/96, para todos os professores que atuam na educação básica, que determina no Artigo 62.

\begin{abstract}
A formação de docentes para atuar na educação básica far-se-á em nível superior, em curso de licenciatura, de graduação plena em universidades e institutos superiores de educação, admitida como formação mínima para o exercício do magistério na educação infantil e nas quatro primeiras séries do ensino fundamental, oferecida em nível médio, na modalidade Normal. (BRASIL. 2010, p. 46).
\end{abstract}

Já no mês de janeiro do ano de 2009, através do Decreto 6.755 , foi instituída a Política Nacional de Formação dos Professores do Magistério da Educação Básica, 
tendo a finalidade de organizar a formação desses profissionais. Com isso o MEC através do PARFOR, atendeu o que a LDB - $\mathrm{N}^{\circ} 9.394 / 96$ exige que todos os professores da educação básica sejam formados.

Durante muito tempo a educação esteve restrita a uma pequena parcela da população, apenas aqueles que tinham certo poder aquisitivo conseguiam títulos mais elevados, e com isso obtinham os melhores cargos no mercado de trabalho. A formação de professores também esteve restrita por muito tempo e os que exerciam não eram cobrados por uma melhor qualificação. Os problemas econômicos e sociais cooperavam para essa desigualdade na busca por uma melhor qualificação, além do descaso por parte do Estado.

O descaso pelo preparo do mestre fazia sentido em uma sociedade não comprometida em priorizar a educação elementar. Além disso, prevalecia à tradição pragmática de acolher professores sem formação. Conforme o pressuposto de que não havia necessidade de nenhum método pedagógico específico. Essa tendência, embora começasse a ser criticada pelo governo, predominaria ainda por muito tempo, em decorrência da concepção "artesanal” da formação do professor (ARANHA, 2006, p. 45).

No entanto, com o passar do tempo essa concepção foi mudando, uma sociedade capitalista não admitiria mais o fracasso na educação. Com isso passou-se a investir mais na educação e principalmente na formação de professores. O Estado passou a fomentar a busca por uma melhor qualificação através de programas, entre eles está o Plano Nacional de Formação de Professores da Educação Básica (PARFOR).

Uma grande porcentagem dos professores atuava na área apenas com o magistério, ou seja, sem diploma superior. Este foi um dos motivos que levou à criação do PARFOR em maio de 2009.

O Plano Nacional de Formação de Professores da Educação Básica é uma ação emergencial que visa estimular a formação em nível superior de professores em exercício nas redes públicas de educação básica. Assim, o programa insere professores que estavam sem a devida qualificação. Quanto aos dados da demanda por curso, observar a Tabela 1.

TABELA 1. Curso de formação docente e percentual preenchido na oferta de vagas de ensino superior no PARFOR nos institutos e universidades públicas no Pará.

\begin{tabular}{ll}
\hline Cursos & Percentual preenchido \\
\hline Pedagogia & $15,46 \%$ \\
Artes & $9,97 \%$
\end{tabular}


Educação Especial

Ciências Naturais/Biológicas

Letras - Língua Portuguesa

Pedagogia do Campo

Matemática
$8,25 \%$

$8,19 \%$

$6,77 \%$

$5,87 \%$

$5,62 \%$

Fonte: www.capes.gov.br

Entre 2009 e 2013, foi ofertado no PARFOR um total de 244.065 vagas. Deste total $70,09 \%$ são cursos de primeira licenciatura, $26,59 \%$ de segunda licenciatura e $3,32 \%$

de

formação pedagógica. Na Tabela 2 é apresentada a distribuição regional das matrículas 2009-2013.

TABELA 2. Distribuição regional e percentual (\%) de matrículas nos cursos de formação docente na educação básica no PARFOR entre 2009 e 2013 no Brasil.

\begin{tabular}{lc}
\hline Região & \% de matrícula por Região \\
\hline Norte & $48,86 \%$ \\
Nordeste & $38,18 \%$ \\
Centro-Oeste & $1,38 \%$ \\
Sul & $7,76 \%$ \\
Sudeste & $3,81 \%$ \\
\hline Total & $\mathbf{1 0 0 \%}$ \\
\hline
\end{tabular}

Fonte: www.capes.gov.br

Esses números demonstram a desigualdade em nosso país, seria ingenuidade pensar que o maior percentual de matrícula seja da região Norte, apenas por uma mera coincidência. É do conhecimento de grande parte dos brasileiros que a região Norte sempre foi esquecida pelo poder público. Deste modo, poucos investimentos são destinados, como por exemplo, na segurança e na saúde. É obvio que a educação também sofre com esse "esquecimento" por parte das nossas autoridades. Acredita-se que esse seja um dos principais fatores que contribuem para uma grande porcentagem de inscritos no PARFOR, tendo em vista que a educação se dá de forma gradativa, e caso o sujeito não tenha uma educação de qualidade, desde a base, dificilmente ele irá concorrer em um nível de igualdade com os demais, que por sua vez tiveram uma melhor preparação. 
Entre 2009 - 2013, um total de 70.220 professores da rede pública efetuou matrícula em 2.145 turmas implantadas. Como já foi visto a região Norte teve o maior índice de matriculados, por uma série de fatores, o principal deles o descaso com a região Norte, ratificando uma desigualdade histórica em nosso país.

\section{CONCLUSÕES}

O trabalho buscou analisar o PARFOR no âmbito das ações afirmativas, além de fazer um pequeno resgate do contexto histórico, passando pela década de 30 do século passado, pelos anos de 1968, 1980, 1988 e 1995 onde é adotada a primeira política de cotas. 2007 também foi importante com a adesão do "Plano de Metas e Compromisso todos pela educação. E finalmente 2009, o ano que foi criado o PARFOR. Foram apresentados alguns dados estatísticos, na intenção de demonstrar, através dos números o quanto o PARFOR tem contribuído na formação de professores.

\section{REFERÊNCIAS BIBLIOGRÁFICAS}

ARANHA, Maria Lúcia de Arruda. Filosofia da educação. $3^{\text {a }}$ ed. São Paulo: Moderna, 2006.

BRASIL. Lei de Diretrizes e Bases da Educação Nacional, Lei No 9394/96.

Ministério da Educação/MEC. de 20 de dezembro de 1996. Brasília: DOU, 23/12/1996.

PIERRÉ-CAPS, Stéphane. O direito das minorias. In: ROULAND, Norbert (Org.). Direito das minorias e dos povos autóctones. Brasília: EdUnB, 2004. p. 65366.

SHIROMA, Eneida Oto; et al. Política educacional. $2^{\mathrm{a}}$ edição. Rio de Janeiro: DP\&A, 2002. 